l'approvisionnement des centres urbains en lait en nature. Bull. Acad. Méd., $1946, \mathrm{n}^{\circ} 6-7-8,125$.

[10] G. Thueulin. Méthode de contrôle hygiénique du lait. Rapport de la Société de Path. Comp., 13 janvier 1942 ; Lait, 1942, XXII, 8.

\title{
SUR UNE MÉTHODE SIMPLE D'ISOLEMENT ET D'ÉTUDE DES FERMENTS DE L'AROME DES BEURRES (1)
}

\author{
par
}

\section{JE AN KEILLING et ANDRÉ CAMUS}

Il est d'usage courant, dans la pratique des laboratoires qui s'occupent des problèmes beurriers, de considérer l'isolement et la conservation des ferments d'arome des beurres comme l'une des tâches les plus difficiles.

Au cours de nos études sur l'amélioration industrielle des fabrications beurrières, il nous a été permis de procéder à un certain nombre de constatations et d'essais à partir desquels nous avons élaboré une nouvelle méthode simple d'isolement et de conservation en culture pure des ferments de l'arome.

Les constatations. - L'aróme du beurre, caractéristique recherchée et appréciée par le commerce et par les consommateurs, apparaît le plus souvent dans un délai relativement restreint, après la fabrication et le malaxage.

S'il est considéré simplement comme un phénomène microbien passager, il semble logique de penser qu'il se développe à la suite d'une fermentation qui a lieu au sein et aux dépens du milieu non gras du beurre. Ce milieu varie en fonction du mode de travail, dans les barattes et sous le malaxeur, des crèmes et beurres considérés, mais il est toujours, en définitive constitué par du lefbeurre plus ou moins dilué par addition d'eau au cours des diverses manipulations de la crème et du beurre.

Cette hypothèse conduit tout naturellement à examiner la fTore microbienne du beurre, non pas sur des milieux de culture riches, tels que le lait digéré ou les produits de digestion des protides de celui-ci, mais sur milieu de culture essentiellement constitués par du lait fortement dilué par addition d'eau avant sa stérilisation.

C'est ainsi que, d'un beurre à l'autre, le liquide non gras que l'on peut extraire est constitué par du babeurre dont les dilutions

(1) Note présentée par $M$. Lemoigne, à l'Académie d'Agriculture (séance du 26 mars 1547). 
aqueuses s'échelonnent entre $1 / 2$ et $1 / 40^{\mathrm{e}}$ de la concentration d'un babeurre théorique qui n'aurait reçu, avant son évacuation de la baratte, aucune addition d'eau.

DILUTION DU LIQUIDE RÉSULTAT DU MALAXAGE DES BEURRES

\begin{tabular}{r|r|r|r|r|r|c}
\hline \hline Eehantillon $\mathrm{n}^{6}$ & 1 & 2 & 3 & 4 & 5 & 6 \\
\hline & & & & & \\
Extrait sec par litre ...... & 14,5 & 4,3 & 2,4 & 4,2 & 6,7 & 2,18 \\
\hline & & & & & \\
\hline $\begin{array}{l}\text { Ditution par rapport au ba- } \\
\text { beurre pur (90 gr. d'ex- } \\
\text { trait sec)............ }\end{array}$ & $1 / 6 \mathrm{e}$ & $1 / 20^{\mathrm{e}}$ & $1 / 40^{\mathrm{e}}$ & $1 / 20^{\mathrm{e}}$ & $1 / 15^{\mathrm{e}}$ & $1 / 40^{\mathrm{e}}$ \\
\hline
\end{tabular}

Cette hypothèse rejoint deux observations fort importantes relevées dans la pratique industrielle :

a) Dans certaines beurreries normandes réputées, le lavage des beurres comporte le plus souvent, après la formation du grain, une addition d'eau jusqu'à remplissage total de la baratte, une agitation puis un repos prolongé dans le récipient complètement plein, d'où, à la fois, possibilité de sédimentation des particules de caséine et dilution extrême du liquide qui demeure en compagnie de la matière grasse ;

b) D'autre part, l'examen microscopique direct des liquides obtenus au cours du malaxage de beurres fermiers normands de qualité, met en évidence la présence de germes nombreux parmi lesquels prédominent streptocoques lactiques à gros éléments et diplocoques producteurs de diacétyle, qui semblent ainsi trouver dans le babeurre dilué un milieu d'élection.

\section{Le mode opératoire. - Nous opérons de la manière sui- vantec}

L'isolement peut ềtre fait à partir de beurre, de crème, de lait ou de babeurre.

S'il s'agit de beurre, eelui-ci est mis à fondre. Le non gras se sépare. $1 \mathrm{~cm}^{3}$ est versé dans un flacon contenant $200 \mathrm{~cm}^{3}$ d'eau stérile gélosée à $1 \%$.

Dans le cas de crème, de lait ou de babeurre, on en prélève $1 \mathrm{~cm}^{3}$ qui est traité de la même façon. On abandonne pendant deux heures à $20^{\circ} \mathrm{C}$, en agitant fréquemment pour maintenir le produit en suspension dans l'eau gélosée. Après ce laps de temps, cette dilution est repiquée à raison de $1 \mathrm{~cm}^{3}$ dans une ou deux séries de tubes contenant respectivement du lait stérile étendu à $50,75,90$, 95 et $98 \%$ avec de l'eau stérile. 
Ces tubes sont maintenus à la température de $18^{\circ} \mathrm{C}$. pendant quarante-huit heures. Passé ce délai, sur chacun d'eux sont pratiqués un examen microscopique et la recherche du diacétyle. L'examen microscopique permet d'éliminer les tubes dans lesquels les streptocoques et les diplocoques recherchés ne constituent pas la flore dominante.

L'épreuve du diacétyle effectuée par la méthode de Hammer à la potasse et à la créatine, ou tout autre méthode qualitative rapide, permet de déterminer la composition du milieu qui convient le mieux à la croissance des ferments d'arome ainsi que la dilution pour laquelle la production de diacétyle est maximum.

Ce choix étant effectué, on pratique ensuite à partir des tubes retenus, et sur le milieu choisi, un isolement rapide par la méthode classique des dilutions successives de Lister. Liexpérience nous a montré qu'en utilisant cette technique, on obtenait des souches pures, pour les dilutions s'échelonnant suivant les cas de 10-9 à 10-14. On achève la purification ou le contrôle de celles-ci à partir d'une culture d'accumulation par passage sur milieu solide au lait dilué digéré par la papaïne ou la trypsine. Par mesure de précaution on s'assure finalement s'il ne s'agit pas de bactéries coliformes ou indologènes.

$$
*^{*} *
$$

Cette méthode nous a permis d'isoler des souches de ferments lactiques producteurs d'arome, qu'il est nécessaire d'entretenir, selon les espèces, sur du lait dilué par l'eau à $50 \%$, à $25 \%$ ou à $10 \%$, ear leur culture prolongée sur lait non dilué nuit fortement à leur -vitalité.

Ces souches produisent de fortes quantités de diacétyle et d'acétylméthylcarbinol.

L'une d'elle est utilisée depuis quatre ans dans la pratique industrielle pour l'ensemencement des crèmes pasteurisées et a donné entière satisfaction. Une des beurreries qui l'emploient a obtenu sans interruption, depuis le 22 janvier 1946 , la prime offerte aux beurres pasteurisés, avec les notes de goût suivantes :

$8 / 10,7 / 10,7,5 / 10,6 / 10,8 / 10,6,5 / 10,6 / 10,8,5 / 10,8 / 10$.

Des beurres fabriqués à partir de crèmes ensemencées a vec cette souche ont présenté à l'analyse des doses de diacétyle allant jusqu'à 4 mgr., 8 par kilogramme. 